\title{
Role of neuropeptides, hormones, and growth factors in regulating thymopoiesis in middle to old age Kalpesh Patel and Dennis D Taub*
}

\author{
Address: Laboratory of Immunology, National Institute of Aging, Intramural Research Program, National Institutes of Health, Biomedical Research \\ Center, 251 Bayview Boulevard, Room 8C222, Baltimore, MD 21224, USA \\ * Corresponding author: Dennis D Taub (taubd@grc.nia.nih.gov) \\ Fl000 Biology Reports 2009, I:42 (doi:I0.34I0/BI-42)
}

The electronic version of this article is the complete one and can be found at: http://FI000.com/Reports/Biology/content/l/42

\begin{abstract}
The deterioration in adaptive immunity and T-lymphocyte output and the narrowing of the $\mathrm{T}$ cell receptor repertoire with age are largely attributable to thymic involution. The loss of thymic function with age may be due to diminished numbers of early thymic progenitors and epithelial cells, and the loss of critical tropic factors within the thymic microenvironment. Here we review some of the recent literature demonstrating a role for neuropeptides, hormones, and growth factors that can influence thymopoiesis associated with stress and aging.
\end{abstract}

\section{Introduction and context}

The presence of a functional immune system is considered critical for a host's survival against the barrage of foreign organisms and pathogens to which we are exposed on a daily basis. In humans and many other species, it has been recognized that the immune system declines with age, a term known as 'immunosenescence', which has been associated with a higher incidence of infections, cancers, and autoimmune diseases [1-4]. Of all the described changes in the immune system with advancing age, the atrophy or involution of the thymus is the most dramatic and ubiquitous. The thymus undergoes a profound age-associated reduction in size due to loss of cellularity and thymic epithelial cells (TECs), and a decrease in thymopoiesis. This loss of de novo T cell generation results in a decline in the generation of cellular responses to new antigens and is associated with a peripheral bias toward the expansion of memory $\mathrm{T}$ cells against prior viral antigens [1-4]. Emerging evidence has strongly suggested that thymic involution, once thought to be a process linked with the onset of puberty (due to increases in sex steroids and a decline in growth hormone $[\mathrm{GH}]$ production, both of which have an impact on thymic function and output), is a continuous process not affected by the changing hormonal balance at puberty [2]. While the precise molecular mechanism involved in the involution process remains obscure, a number of theories have been proposed to explain this 'thymic menopause', including alterations in the expression of critical cytokines, neuropeptides, and/or growth factors within the thymic environment of the aging host [1-3]. We shall discuss some of the more recent advances in this area below.

\section{Major recent advances}

Neuropeptides, hormones, and growth factors produced by various organ systems have long been associated with effects on immune cell function [5,6] (Figure 1). Growthand activation-promoting effects on a number of immune cell populations as well as growth-stimulating effects on the thymus have been reported $[1,2,5]$. Here, we review the more recent advances of several hormones, neuropeptides, and growth factors in influencing thymopoiesis and age-associated thymic loss.

\section{Growth hormone}

It has been shown that both circulating and thymic levels of GH decrease with age and that the diminished levels of GH occur during the more dramatic stages of thymic involution $[1,2]$. It has been demonstrated that impaired 
Figure I. Neuropeptide interactions with the thymus

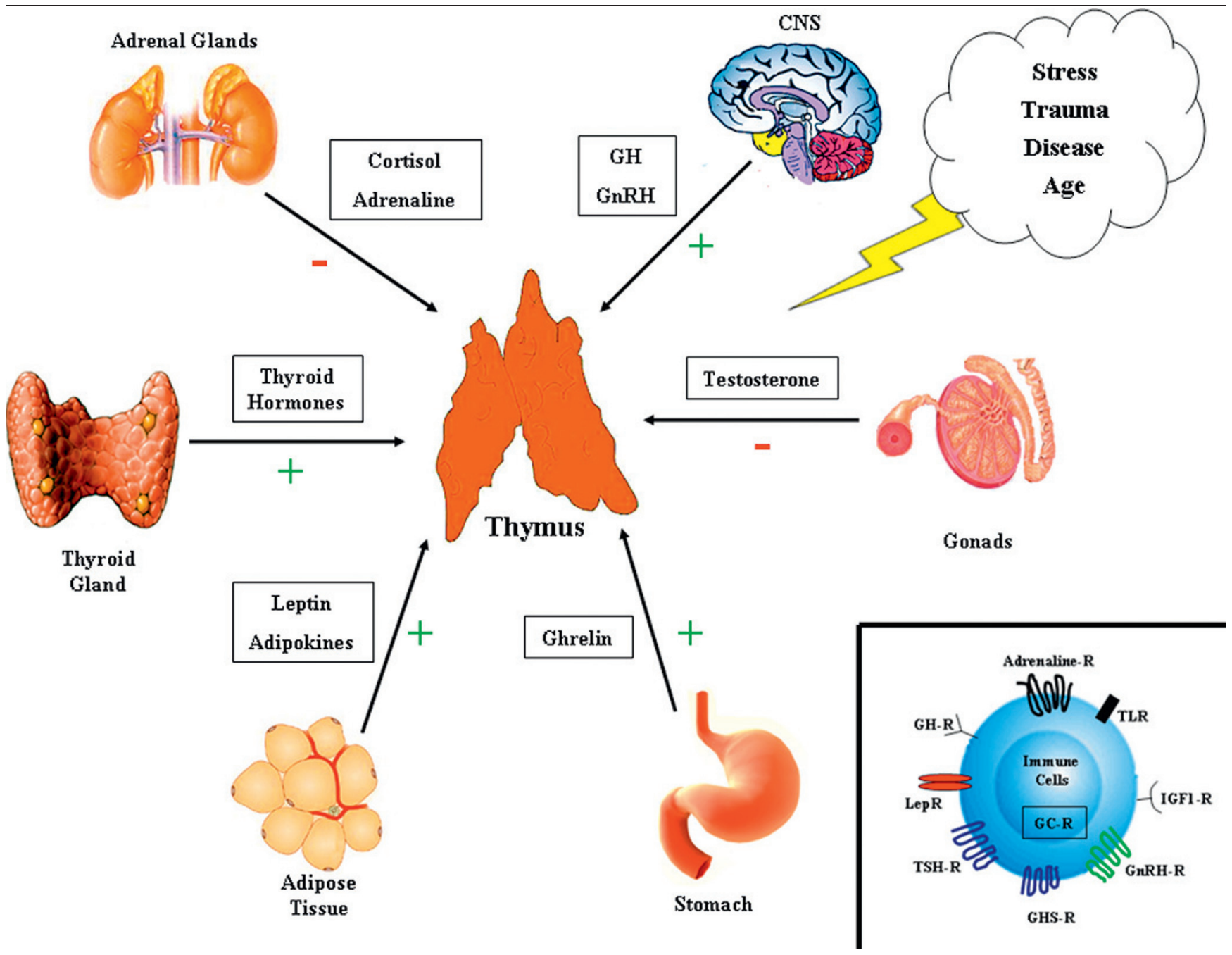

The crosstalk between the various neuronal, endocrine and immune systems appears to be mediated via the production of interactions with soluble immune and neuroendocrine mediators. Several hormonal and neuropeptide systems, including sex hormones (such as testosterone and growth hormone secretagogue receptor), adrenal and thyroid hormones (corticosteroids, cortisol, adrenaline, and thyroid-stimulating hormone), pituitary hormones (growth hormone), and metabolic hormones (leptin, ghrelin, and insulin-like growth factor-I), have been shown to influence immune activation and thymic function. These mediators provide the link between the endocrine, central nervous, and immune systems and constitute specific axes of interactions. Immune cells, in their resting state or upon activation, express cell surface receptors for these hormones and peptides, permitting responses to these ligands. In states of stress, trauma, and disease and during aging, these organ systems are activated and release mediators to facilitate crosstalk with the immune system, affecting both thymopoiesis and hematopoiesis. The immune system similarly produces factors that feedback and communicate with these organ systems. CNS, central nervous system; GC, glucocorticoid; GH, growth hormone; GHS, growth hormone secretagogue; $\mathrm{GnRH}$, gonadotropin-releasing hormone; IGF-I, insulin-like growth factor; LepR, leptin receptor; R, receptor; TLR, Toll-like receptor; TSH, thyroidstimulating hormone.

thymic function could be restored upon administration of exogenous GH in hormone-deficient dwarf and aged mice $[1,2,5-7]$. Napolitano and colleagues [8] recently reported that infusion of GH in HIV-1-infected patients increased thymic mass and output as well as the number of circulating naïve and total $\mathrm{CD} 4^{+} \mathrm{T}$ cells and thymic T cell output in the circulation. Knockout mouse and various stress models have also suggested that GH may directly and/or indirectly promote T-progenitor cell survival during conditions of trauma and stress [1,5,7]. GH should be assessed clinically for the ability to promote (a) thymus regeneration and production of naïve $T$ cells in adults and (b) multilineage hematopoietic recovery from myeloablative therapy. Despite these findings, it seems likely that 
GH may not be required for normal lymphoid and myeloid development. However, under conditions of stress and trauma, GH stimulates proliferation, exerts antiapoptotic effects, and amplifies signals associated with lymphoid and myeloid cell expansion.

\section{Insulin-like growth factor-I}

Insulin-like growth factor-1 (IGF-1) has also been of particular interest in the context of thymic involution, as this hormone steadily declines with age in rodents and humans, whereas IGF-1 treatment increases thymic cellularity and T-cell output in mice, possibly due to its anti-apoptotic effects $[1,2,4,5,9]$. Mice lacking IGF-1 receptor (IGF-1R) on thymocytes demonstrate decreased thymic output, which can be reversed by IGF-1 infusion [10]. IGF-1 infusion increased peripheral naïve and recent thymic emigrant populations, demonstrating a direct effect on $\mathrm{T}$ cell production, not peripheral expansion. IGF-1 administration also increased bone marrow LSK $\left(\mathrm{Lin}^{-} \mathrm{Sca}-1^{+} \mathrm{c}-\mathrm{Kit}^{+}\right)$cell precursor proliferation, peripheral LSK cell populations and thymocyte populations, and proportionately expanded TEC subpopulations and enhanced their chemokine expression. These results suggest that IGF-1R expression on TECs plays an important role in facilitating the increased thymic cellularity and $\mathrm{T}$ cell output in response to IGF-1 administration.

\section{Leptin}

Leptin, an anorexigenic hormone that exerts significant effects on immune responses and induces proinflammatory cytokine expression [3], is produced predominantly by fat cells and controls food intake and energy balance. Leptin (ob/ob) and leptin receptor $(\mathrm{db} / \mathrm{db})$ mutant mice are born with significant thymic atrophy, and reinfusion of leptin into ob/ob results in thymic restoration [11]. Leptin infusion also prevents thymus weight loss after lipopolysaccharide treatment but failed to stimulate thymopoiesis [12]. Moreover, leptin infusion increases thymocytes and TEC numbers, reduces apoptosis, and increases $\mathrm{T}$ cell output and peripheral $\mathrm{T}$ cell receptor (TCR) diversity in aged mice [13].

\section{Ghrelin}

Ghrelin is an orexigenic hormone characterized initially as a GH secretagogue (GHS), secreted predominantly by the stomach cells. More recently, ghrelin has been found to be secreted by immune cells as well. Ghrelin and its receptor, GHSR, are expressed in the thymus, and ghrelin has been shown to induce thymic GH expression, which may play a major role in enhancing thymopoiesis $[1,2,5,6,13]$. Infusion of ghrelin in old mice significantly improved the age-associated loss of thymocyte numbers and de novo T cell output, and also increased peripheral TCR diversity [13]. Ghrelin increased early thymic progenitors in the thymus. Similarly, ghrelin- and GHSR-deficient mice demonstrate an accelerated ageassociated thymic involution, which may be associated with reduced TEC numbers in the thymus [14].

\section{Steroidal hormones}

Ablation of sex steroids like testosterone, via castration or chemical castration or through the administration of steroid antagonists, has been shown to induce a profound increase in thymic mass and cellularity and enhanced $\mathrm{T}$ cell output in aged mice. These changes are maintained for quite some time and even temporary sex steroid ablation may have a significant impact on thymic activity and the circulating T cell repertoire [15]. A recent study has shown that castration induces the proliferation of medullary TECs, which results in the increased expression of the chemokine CCL25 that assists in recruiting more thymocyte progenitors, thus enhancing thymopoiesis [16]. Neutralization of CCL25 prevented thymocyte development and abrogated the increased thymic cellularity and $\mathrm{T}$ cell output observed in response to castration [16]. Together, these data have provided new insight into the role of steroidal hormones in thymic development and atrophy.

\section{Keratinocyte growth factor}

Keratinocyte growth factor (KGF) increases thymocyte numbers via induction of triple-negative cell division and also increased double-positive cells and thymic output. KGF induces the expression of additional growth factors in the thymus to exert these effects [17]. KGF infusion enhances thymic cellularity, increases naïve $\mathrm{CD}^{+} \mathrm{T}$ cell output, and increases antibody production in aged mice [18]. KGF also increases the number of TECs, reorganizes thymic architecture, and increases interleukin-7 expression, which is critical for thymocyte development, in aged mice as well as in an aging model using Klotho knockout (kl/kl) mice. $\mathrm{kl} / \mathrm{kl}$ mice develop premature thymic atrophy and disruption of thymic microenvironmental organization, which can be restored by KGF infusion [19].

\section{Other factors}

There are numerous cytokines, growth factors, glucocorticoids, neurotrophins, and thymic hormones that have been shown to influence thymic development and integrity in response to stress and age. Although it is beyond the scope of this literature update to discuss all of these systems and neuropeptides, several review articles discussing the expression of these neuropeptides and growth factors within immune tissues and their effects 
on thymic activity during development, puberty, stress, immunosuppression, and aging are available $[1,2,7,9,12,15,20-28]$.

\section{Future directions}

The central nervous, endocrine, and immune systems cross-communicate with each other through multiple anatomical and hormonal neuropeptide routes. Interactions between these systems are highly controlled and are critical for the maintenance of a homeostatic balance within the body. Any alterations in the balance between these systems in response to disease, stress, or injury may lead to significant changes in thymic development and immune responsiveness. While significant progress has been made in many areas of study, more focused studies are needed to assess the biological and molecular roles that each of these neuropeptides and hormones plays in hematopoiesis and thymopoiesis and how disruption within one or more of these compartments may influence a host's ability to regulate inflammation, disease development, or wound healing. Understanding such relationships may reveal possible therapeutics to restore and optimize thymic function.

\section{Abbreviations}

$\mathrm{GH}$, growth hormone; GHS, growth hormone secretagogue; GHSR, growth hormone secretagogue receptor; IGF-1, insulin-like growth factor-1; IGF-1R, insulin-like growth factor-1 receptor; KGF, keratinocyte growth factor; kl/kl, Klotho knockout; LSK, $\mathrm{Lin}^{-} \mathrm{Sca}^{+}{ }^{+} \mathrm{c}-\mathrm{Kit}^{+}$; TCR, T cell receptor; TEC, thymic epithelial cell.

\section{Competing interests}

The authors declare that they have no competing interests.

\section{Acknowledgments}

This research was supported in part by the Intramural Research Program of the National Institute on Aging of the National Institutes of Health.

\section{References}

I. Taub DD, Longo DL: Insights into thymic aging and regeneration. Immunol Rev 2005, 205:72-93.

2. Montecino-Rodriquez E, Min H, Dorshkind K: Reevaluating current models of thymic involution. Semin Immunol 2005, | 7:356-61.

3. Aw D, Silva $A B$, Palmer DB: Immunosenescence: emerging challenges for an ageing population. Immunol 2007, I 20:435-46.

4. Dorshkind K, Montecino-Rodriguez E, Signer RA: The ageing immune system: is it ever too old to become young again? Nat Rev Immunol 2009, 9:57-62.

5. Taub DD: Neuroendocrine interactions in the immune system. Cell Immunol 2008, 252:1-6.
6. Taub DD: Novel connections between the neuroendocrine and immune systems: the ghrelin immunoregulatory network. Vitam Horm 2008, 77:325-46.

7. Redelman D, Welniak LA, Taub D, Murphy WJ: Neuroendocrine hormones such as growth hormone and prolactin are integral members of the immunological cytokine network. Cell Immunol 2008, 252:I I I-2I.

8. Napolitano LA, Schmidt D, Gotway MB, Ameli N, Filbert EL, Ng MM, Clor JL, Epling L, Sinclair E, Baum PD, Li K, Killian ML, Bacchetti P, McCune JM: Growth hormone enhances thymic function in HIV-I-infected adults. J Clin Invest 2008, I I 8: I 085-98.

FI000 Factor 3.0 Recommended

Evaluated by Nelson Chao 17 Mar 2008

9. Dorshkind $\mathrm{K}$, Horseman ND: The roles of prolactin, growth hormone, insulin-like growth factor-I, and thyroid hormones in lymphocyte development and function: insights from genetic models of hormone and hormone receptor deficiency. Endocr Rev 2000, $21: 292-312$.

10. Chu YW, Schmitz S, Choudhury B, Telford W, Kapoor V, Garfield S, Howe D, Gress RE: Exogenous insulin-like growth factor I enhances thymopoiesis predominantly through thymic epithelial cell expansion. Blood 2008, I I 2:2836-46.

II. Howard JK, Lord GM, Matarese G, Vendetti S, Ghatei MA, Ritter MA, Lechler RI, Bloom SR: Leptin protects mice from starvationinduced lymphoid atrophy and increases thymic cellularity in ob/ob mice. J Clin Invest 1999, 104:1051-9.

12. Hick RW, Gruver AL, Ventevogel MS, Haynes BF, Sempowski GD: Leptin selectively augments thymopoiesis in leptin deficiency and lipopolysaccharide-induced thymic atrophy. J Immunol 2006, I77:169-76.

13. Dixit VD, Yang H, Sun Y, Weeraratna AT, Youm YH, Smith RG, Taub DD: Ghrelin promotes thymopoiesis during aging. J Clin Invest 2007, I I 7:2778-90.

14. Youm YH, Yang H, Sun Y, Smith RG, Manley NR, Vandanmagsar B, Dixit VD: Deficient ghrelin receptor-mediated signaling compromises thymic stromal cell microenvironment by accelerating thymic adiposity. J Biol Chem 2009, 284:7068-77.

15. Hince M, Sakkal S, Vlahos K, Dudakov J, Boyd R, Chidgey A: The role of sex steroids and gonadectomy in the control of thymic involution. Cell Immunol 2008, 252:122-38.

16. Williams KM, Lucas PJ, Bare CV, Wang J, Chu YW, Tayler E, Kapoor V, Gress RE: CCL25 increases thymopoiesis after androgen withdrawal. Blood 2008, I | 2:3255-63.

17. Rossi SW, Jeker LT, Ueno T, Kuse S, Keller MP, Zuklys S, Gudkov AV, Takahama Y, Krenger W, Blazar BR, Holländer GA: Keratinocyte growth factor (KGF) enhances postnatal T-cell development via enhancements in proliferation and function of thymic epithelial cells. Blood 2007, I09:3803-II.

18. Min D, Panoskaltsis-Mortari A, Kuro-O M, Holländer GA, Blazar BR, Weinberg KI: Sustained thymopoiesis and improvement in functional immunity induced by exogenous KGF administration in murine models of aging. Blood 2007, 109:2529-37.

19. Kelly RM, Highfill SL, Panoskaltsis-Mortari A, Taylor PA, Boyd RL, Holländer GA, Blazar BR: Keratinocyte growth factor and androgen blockade work in concert to protect against conditioning regimen-induced thymic epithelial damage and enhance $\mathrm{T}$-cell reconstitution after murine bone marrow transplantation. Blood 2008, I I I:5734-44.

20. Steinman L: Elaborate interactions between the immune and nervous systems. Nat Immunol 2004, 5:575-8I.

21. Butts $C L$, Sternberg EM: Neuroendocrine factors alter host defense by modulating immune function. Cell Immunol 2008, 252:7-15.

22. O'Connor JC, McCusker RH, Strle K, Johnson RW, Dantzer R, Kelley KW: Regulation of IGF-I function by proinflammatory cytokines: at the interface of immunology and endocrinology. Cell Immunol 2008, 252:91-I I0. 
23. Haynes BF, Sempowski GD, Wells AF, Hale LP: The human thymus during aging. Immunol Res 200I, 22:253-6I.

24. Turrini $P$, Zaccaria ML, Aloe L: Presence and possible functional role of nerve growth factor in the thymus. Cell Mol Biol (Noisy-legrand) 200I, 47:55-64.

25. Kinoshita $Y$, Hato F: Cellular and molecular interactions of thymus with endocrine organs and nervous system. Cell Mol Biol (Noisy-le-grand) 200I, 47:103-17.
26. Dardenne M: Role of thymic peptides as transmitters between the neuroendocrine and immune systems. Ann Med 1999, 3I:34-9.

27. Silva $A B, A w D$, Palmer $D B$ : Evolutionary conservation of neuropeptide expression in the thymus of different species. Immunol 2006, I I 8: I3I-40.

28. Silva $A B, A w D$, Palmer DB: Neuropeptides and thymic hormones in the Xenopus thymus. Front Biosci 2009, 14:1990-2003. 